\title{
Review Article \\ Sweet Bones: The Pathogenesis of Bone Alteration in Diabetes
}

\author{
Mohammed Al-Hariri \\ Department of Physiology, College of Medicine, University of Dammam, P. O. Box 2114-31451, Dammam, Saudi Arabia
}

Correspondence should be addressed to Mohammed Al-Hariri; mohd_alhariri@yahoo.com

Received 17 July 2016; Accepted 15 September 2016

Academic Editor: Ilias Migdalis

Copyright (C) 2016 Mohammed Al-Hariri. This is an open access article distributed under the Creative Commons Attribution License, which permits unrestricted use, distribution, and reproduction in any medium, provided the original work is properly cited.

Diabetic patients have increased fracture risk. The pathogenesis underlying the status of bone alterations in diabetes mellitus is not completely understood but is multifactorial. The major deficits appear to be related to a deficit in mineralized surface area, a decrement in the rate of mineral apposition, deceased osteoid surface, depressed osteoblast activity, and decreased numbers of osteoclasts due to abnormal insulin signaling pathway. Other prominent features of diabetes mellitus are an increased urinary excretion of calcium and magnesium, accumulation of advanced glycation end products, and oxidative stress leading to sweet bones (altered bone's strength, metabolism, and structure). Every diabetic patient should be assessed for risk factors for fractures and osteoporosis. The pathogenesis of the bone alterations in diabetes mellitus as well as their molecular mechanisms needs further study.

\section{Introduction}

Diabetes mellitus is a common chronic hyperglycemic, prevalent disease, with significant associated mortality and morbidity that affects millions of population worldwide. It is associated with a variety of complications that are well known to healthcare providers. In time, the bones may also be affected, in addition to many other organs. However, the status of bones as well as their disorders in patients with diabetes mellitus has received very little attention. This is surprising because bone disease in diabetes mellitus is probably as old as the disease itself since descriptions of bone disease in diabetes can be traced as far back as the 1920s and is as old as insulin itself [1]. Vestergaard et al. (2009) concluded that diabetes, whether type 1 diabetes (T1D) or type 2 diabetes (T2D), seems to carry an increased risk of fractures [2]. Recent studies have identified an impairment of bone quality and a higher risk of fracture, in those with T2D [3].

During the last two decades, studies reported that T2D is associated with up to three times increased risk of fracture $[4,5]$.

\section{Pathogenesis of Sweet Bones}

There are different mechanisms that can be proposed to explain the pathogenesis of sweet bones in diabetes mellitus, summarised in Figure 1.
Insulin signaling has a metabolic and mitogenic effect on osteoblast cells. Current evidence in experimental models with impaired insulin signaling exhibited both metabolic and bone phenotypes, including obesity, insulin intolerance/resistance, and symptoms of low bone mass [6] and the qualitatively different effects of T1D and T2D on bone mass are consistent with the opposing insulin-secretory states [hypoinsulinaemia versus hyperinsulinaemia] [7].

Diabetes could impact bone through several mechanisms, some of which may have contradictory effects. There are many reasons why diabetics are likely to develop bone disease and sustain fractures [8]. Many studies have suggested that low bone mineral density (BMD) is already apparent at the time of diagnosis $[9,10]$.

In T1D, for instance, patients may not attain the full potential of peak adult bone mass because of lower insulinlike growth factor 1 levels and the catabolic effects of frequent uncontrolled hyperglycemia during critical growth period [11]. Altered vitamin D and calcium metabolism due to hyperglycemia in diabetes mellitus can lead to low bone mass and increase chances of fractures $[12,13]$.

A number of studies demonstrated that osteopenia and osteoporosis are frequent complications of T1D [14], as a result of increased oxidative stress [15], as well as to the alteration of osteoblastic function [16].

Since almost $40 \%$ of the skeletal calcium is accumulated between the ages of 10 and 15 years, precisely the time when 


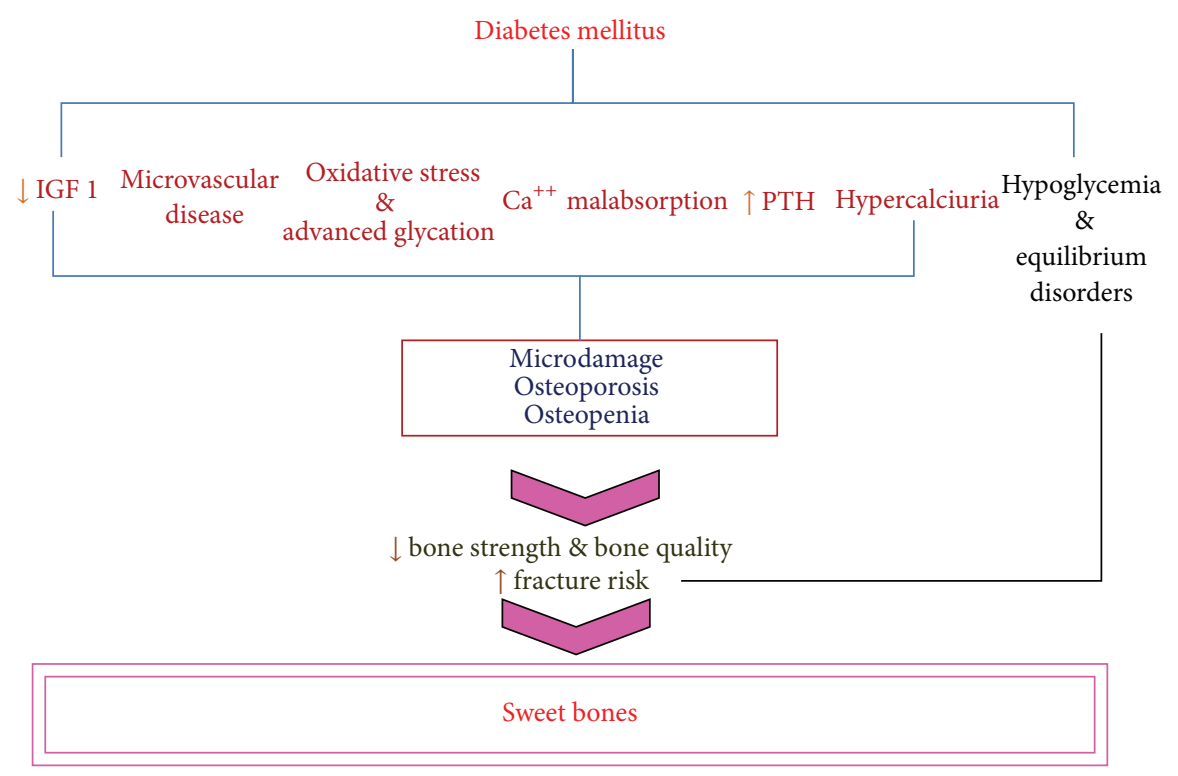

FIGURE 1: The pathogenesis of bone alteration in diabetes.

diabetes control may not be optimal, developing diabetes at this critical juncture may adversely affect the potential to achieve peak adult bone mass. It was reported that a significant number of patients with diabetes may have associated hypovitaminosis-D and calcium malabsorption or both [17, 18], low body mass, overt or subclinical malabsorption such as cystic fibrosis or celiac sprue $[19,20]$, and a higher incidence of subclinical eating behavior disorders, contributing to poor weight maintenance and/or relative malnutrition [21].

With the increasing life expectancy of many diabetic patients, the age related decline in osteoblast function contributes to the pathogenesis of bone loss and recurrent fractures [22].

Diabetes mellitus is known to cause advanced glycation of a variety of proteins that may also include glycation of type I collagen in bone and thus compromise its integrity [11].

Furthermore, peripheral vascular disease is common in this disease which may also contribute to the bone disease and fractures. Reduced interstitial bone fluid flow as a result of diabetic microvascular disease may result in osteocyte apoptosis and reduced osteocyte density leading to increased fragility of bone [23].

In contrast, the occurrence of bone disease in T2D presents an apparent paradox [8], but Takeuchi (2009) in his review reported that bone fragility due to poor bone quality is a major problem in patients with T2D [24]. It has been documented that T2D cases with high bone turnover assuredly predisposed to osteoporosis [25]. Obesity prevalent in T2D is strongly associated with higher BMD probably through mechanical loading and hormonal factors including insulin, estrogen, and leptin [26, 27].

A long-term T1D model showed that diabetic bones display specific defects of bone mineralization, including decreased hydroxyapatite crystal perfection, decreased calcium-to-phosphate composition of the ash, and decreased ash content in certain bones such as the tibial metaphysis.
It also found that the bones from diabetic animals exhibited reduced strength-related properties, along with a compensatory increase in stiffness, suggesting a possible alteration in bone crystal structure [28].

In a number of T1D animal studies, histomorphometric analyses have shown that, irrespective of the model used, insulin-deficient rats may exhibit reduced or absent bone formation and this decline is appreciated in relation to all bone surfaces examined $[29,30]$.

The major deficits in the insulin-deficient models appear to be related to a deficit in mineralized surface area, a decrement in the rate of mineral apposition, deceased osteoid surface, depressed osteoblast activity, and decreased numbers of osteoclasts [31], leading to an overall depression in remodeling of bone in the untreated insulin-deficient state.

Moreover, unlike patients with T1D, T2D patients have higher levels of insulin-like growth factor 1, which is known to stimulate bone formation. Indeed, there is suggestive evidence that age related bone loss is attenuated and bone turnover is either normal or reduced in patients with T2D ([32] and [33]). However, the existence of an elevated fracture risk in $\mathrm{T} 2 \mathrm{D}$, despite the underlying hyperinsulinaemia, suggests the involvement of other potential pathogenic influences (e.g., hyperglycemia, diabetic complications, and lifestyle factors) on bone [7]. In the experimental model, the skeletal fragility in T2D may arise from reduced transverse bone accrual and increased osteoclastogenesis during growth that is accelerated by the diabetic/hyperinsulinemic milieu [34]. Therefore, bone density at relevant measurement sites may not reflect the true quality of the skeleton in patients with T2D; in other words the quantity of bone may be normal but the quality is not.

All of these confounding variables may have independent negative impacts upon bone mineral acquisition in diabetes mellitus and, ultimately, on peak bone mass. On the other hand, low levels of insulin associated with T1D 


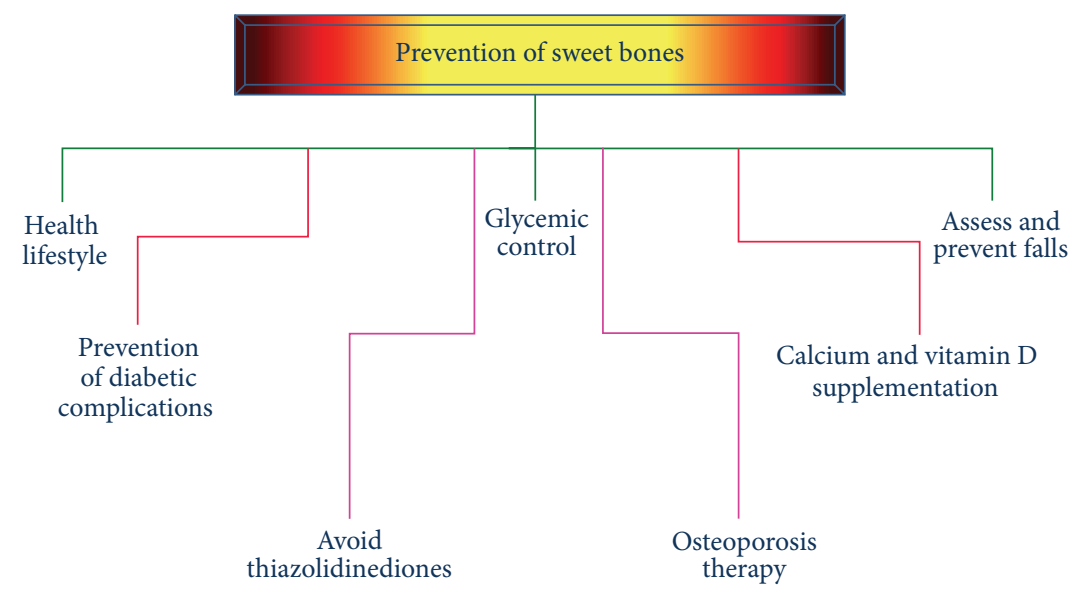

Figure 2: Preventive measures of sweet bones.

and the progression of T2D may cause reductions in $\mathrm{BMD}$. Hyperglycemia generates a higher concentration of advanced glycation end products in collagen that may reduce bone strength [35].

T1D in humans has frequently been shown to be associated with reduced bone mass [36] and a reduced bone mineral content [37]. The percentage of patients reported to have osteopenia ranges from 18 to 54\% [38]. Low turnover osteopenia with reduced mineral content has also been well documented in experimental models of T1D, such as streptozotocin-induced diabetes [39]. Another prominent feature of human and experimental T1D is an increased urinary excretion of calcium and magnesium [40].

Plasma calcium concentration in the rat is normally maintained in the face of such renal losses; a decreased bone mineral content may therefore represent an unfortunate consequence of the marked hypercalciuria serving to maintain normocalcaemia under these conditions [40].

Delayed and impaired fracture's healing in patients with diabetes mellitus has been described in many studies $[41,42]$. Diabetes impairs the production of critical growth factors such as transforming growth factor-beta, insulin-like growth factor 1, vascular endothelial growth factor, and plateletderived growth factor at the fracture site during the early phases of diabetic fracture healing which has been associated with decreased cell differentiation and proliferation $[43,44]$. Previous studies have demonstrated a reduction in collagen synthesis in diabetic rats [45] which ultimately influences bone healing.

Some fractures that frequently occur in diabetic patients may not be related to the systemic effect of diabetes on the skeleton but rather may be due to hypoglycemia, neuropathy, loss of proprioception balance, and coordination that are common in this disease and an important risk factor for falling $[46,47]$.

\section{Prevention of Sweet Bones}

Prevention of any disease is a laudable goal. When this is applied to diabetes mellitus, it gains further importance because of the fact that this disease is gaining epidemic proportion and the cost of treatment of its complications. Sweet bone can be prevented or delayed by making some changes in lifestyle and weight loss, accompanied by increased physical activity to prevent bone loss. Intensive insulin therapy is the standard treatment for T1D and seems to be associated with improved skeletal health $[48,49]$. Systematic screening for diabetic complications such as polyneuropathy, retinopathy, and nephropathy is important. Laser therapy might prevent progression of advanced retinopathy and help to maintain vision [50]. Deficiencies of calcium and vitamin $\mathrm{D}$ in patients with diabetes mellitus should be treated. Vitamin D supplementation should ensure a serum 25-hydroxyvitamin D level of $75 \mathrm{nmol} / \mathrm{L}$ [51]. Attention should be paid to the use of thiazolidinediones, especially in postmenopausal women with T2D. It causes bone loss accompanied by decreased osteoblast activity and bone formation [52]. Assessment of osteoporosis is similar in patients with and without diabetes mellitus. Selection of specific osteoporosis drugs is frequently based on comorbidities [53] (Figure 2).

\section{Conclusion}

Nevertheless, awareness of sweet bone in a patient with diabetes mellitus is important in clinical practice. Early recognition and appropriate intervention are essential in avoiding sweet bones and its consequences in diabetic patient.

Every diabetic patient should be assessed for risk factors for fractures and osteoporosis according to the guidelines established by The International Society for Clinical Densitometry and The National Osteoporosis Foundation. The pathogenesis of the bone alterations in diabetes mellitus as well as their molecular mechanisms needs further study.

\section{Competing Interests}

The author declares that there is no conflict of interests regarding the publication of this paper. 


\section{References}

[1] R. T. Dauphine, B. L. Riggs, and D. A. Scholz, "Back pain and vertebral crush fractures: an unemphasized mode of presentation for primary hyperparathyroidism," Annals of Internal Medicine, vol. 83, no. 3, pp. 365-367, 1975.

[2] P. Vestergaard, L. Rejnmark, and L. Mosekilde, "Diabetes and its complications and their relationship with risk of fractures in type 1 and 2 diabetes," Calcified Tissue International, vol. 84, no. 1, pp. 45-55, 2009.

[3] J. N. Farr and S. Khosla, "Determinants of bone strength and quality in diabetes mellitus in humans," Bone, vol. 82 , pp. 2834, 2016.

[4] M. Janghorbani, R. M. Van Dam, W. C. Willett, and F. B. Hu, "Systematic review of type 1 and type 2 diabetes mellitus and risk of fracture," American Journal of Epidemiology, vol. 166, no. 5, pp. 495-505, 2007.

[5] P. Vestergaard, "Discrepancies in bone mineral density and fracture risk in patients with type 1 and type 2 diabetes-a metaanalysis," Osteoporosis International, vol. 18, no. 4, pp. 427-444, 2007.

[6] S. N. Pramojanee, M. Phimphilai, N. Chattipakorn, and S. C. Chattipakorn, "Possible roles of insulin signaling in osteoblasts," Endocrine Research, vol. 39, no. 4, pp. 144-151, 2014.

[7] S. Adami, "Bone health in diabetes: considerations for clinical management," Current Medical Research and Opinion, vol. 25, no. 5, pp. 1057-1072, 2009.

[8] D. A. Nelson and S. J. Jacober, "Why do older women with diabetes have an increased fracture risk?" The Journal of Clinical Endocrinology \& Metabolism, vol. 86, no. 1, pp. 29-31, 2001.

[9] P.-J. López-Ibarra, M. M. C. Pastor, F. Escobar-Jiménez et al., "Bone mineral density at time of clinical diagnosis of adultonset type 1 diabetes mellitus," Endocrine Practice, vol. 7, no. 5, pp. 346-351, 2001.

[10] B. Piepkorn, P. Kann, T. Forst, J. Andreas, A. Pfützner, and J. Beyer, "Bone mineral density and bone metabolism in diabetes mellitus," Hormone and Metabolic Research, vol. 29, no. 11, pp. 584-591, 1997.

[11] M. E. Garay-Sevilla, L. E. Nava, J. M. Malacara, K. Wróbel, K. Wróbel, and U. Pérez, "Advanced glycosylation end products (AGEs), insulin-like growth factor-1 (IGF-1) and IGF-binding protein-3 (IGFBP-3) in patients with Type 2 diabetes mellitus," Diabetes/Metabolism Research and Reviews, vol. 16, no. 2, pp. 106-113, 2000.

[12] H. Tanaka, T. Hamano, N. Fujii et al., "The impact of diabetes mellitus on vitamin D metabolism in predialysis patients," Bone, vol. 45, no. 5, pp. 949-955, 2009.

[13] R. Ziegler, "Diabetes mellitus and bone metabolism," Hormone and Metabolic Research, Supplement, vol. 26, pp. 90-94, 1992.

[14] F. Lumachi, V. Camozzi, V. Tombolan, and G. Luisetto, "Bone mineral density, osteocalcin, and bone-specific alkaline phosphatase in patients with insulin-dependent diabetes mellitus," Annals of the New York Academy of Sciences, vol. 1173, supplement 1, pp. E64-E67, 2009.

[15] Y. Hamada, H. Fujii, R. Kitazawa, J. Yodoi, S. Kitazawa, and M. Fukagawa, "Thioredoxin-1 overexpression in transgenic mice attenuates streptozotocin-induced diabetic osteopenia: a novel role of oxidative stress and therapeutic implications," Bone, vol. 44, no. 5, pp. 936-941, 2009.

[16] D. Lozano, L. F. de Castro, S. Dapía et al., "Role of parathyroid hormone-related protein in the decreased osteoblast function in diabetes-related osteopenia," Endocrinology, vol. 150, no. 5, pp. 2027-2035, 2009.

[17] B. Basha, D. S. Rao, Z.-H. Han, and A. M. Parfitt, "Osteomalacia due to vitamin D depletion: a neglected consequence of intestinal malabsorption," The American Journal of Medicine, vol. 108, no. 4, pp. 296-300, 2000.

[18] A. A. Tahrani, A. Ball, L. Shepherd, A. Rahim, A. F. Jones, and A. Bates, "The prevalence of vitamin D abnormalities in South Asians with type 2 diabetes mellitus in the UK," International Journal of Clinical Practice, vol. 64, no. 3, pp. 351-355, 2010.

[19] D. R. Curran, J. R. McArdle, and J. S. Talwalkar, "Diabetes mellitus and bone disease in cystic fibrosis," Seminars in Respiratory and Critical Care Medicine, vol. 30, no. 5, pp. 514-530, 2009.

[20] S. L. Elkin, A. Fairney, S. Burnett et al., "Vertebral deformities and low bone mineral density in adults with cystic fibrosis: a cross-sectional study," Osteoporosis International, vol. 12, no. 5, pp. 366-372, 2001.

[21] K. M. Thrailkill, "Diabetes care for adolescents," in Diabetes in Women: Adolescence, Pregnancy and Menopause, Lippincott Williams \& Wilkins, Philadelphia, Pa, USA, 3rd edition, 2004.

[22] A. M. Parfitt, Z.-H. Han, S. Palnitkar, D. S. Rao, M.-S. Shih, and D. Nelson, "Effects of ethnicity and age or menopause on osteoblast function, bone mineralization, and osteoid accumulation in iliac bone," Journal of Bone and Mineral Research, vol. 12, no. 11, pp. 1864-1873, 1997.

[23] S. J. Qiu, S. Palnitkar, and D. S. Rao, "Age-related changes in osteocyte density and distribution in human cancellous bone," Journal Of Bone \& Mineral Research, vol. 14, supplement 1, p. S308, 1999.

[24] Y. Takeuchi, "Overview: derangement of bone metabolism in diabetes mellitus," Clinical Calcium, vol. 19, no. 9, pp. 1247-1255, 2009.

[25] P. Pooruk, N. Kittimanon, P. Janthorn, and N. Bunyaratavej, "The impacts of type 2 diabetes mellitus on bone markers in the elderly Thai women," Journal of the Medical Association of Thailand, vol. 92, pp. S45-S48, 2009.

[26] T. Thomas, B. Burguera, L. J. Melton III et al., "Role of serum leptin, insulin, and estrogen levels as potential mediators of the relationship between fat mass and bone mineral density in men versus women," Bone, vol. 29, no. 2, pp. 114-120, 2001.

[27] D. T. Felson, Y. Zhang, M. T. Hannan, and J. J. Anderson, "Effects of weight and body mass index on bone mineral density in men and women: the Framingham study," Journal of Bone and Mineral Research, vol. 8, no. 5, pp. 567-573, 1993.

[28] T. A. Einhorn, A. L. Boskey, C. M. Gundberg, V. J. Vigorita, V. J. Devlin, and M. M. Beyer, "The mineral and mechanical properties of bone in chronic experimental diabetes," Journal of Orthopaedic Research, vol. 6, no. 3, pp. 317-323, 1988.

[29] J. Verhaeghe, A. M. H. Suiker, B. L. Nyomba et al., "Bone mineral homeostasis in spontaneously diabetic BB rats. II. Impaired bone turnover and decreased osteocalcin synthesis," Endocrinology, vol. 124, no. 2, pp. 573-582, 1989.

[30] J. Verhaeghe, W. J. Visser, T. A. Einhorn, and R. Bouillon, "Osteoporosis and diabetes: lessons from the diabetic BB rat," Hormone Research in Paediatrics, vol. 34, no. 5-6, pp. 245-248, 1990.

[31] J. Verhaeghe, A. M. H. Suiker, W. J. Visser, E. Van Herck, R. Van Bree, and R. Bouillon, "The effects of systemic insulin, insulinlike growth factor-I and growth hormone on bone growth and turnover in spontaneously diabetic BB rats," Journal of Endocrinology, vol. 134, no. 3, pp. 485-492, 1992. 
[32] J. C. Krakauer, M. J. McKenna, N. F. Buderer, D. Sudhaker Rao, F. W. Whitehouse, and A. Michael Parfitt, "Bone loss and bone turnover in diabetes," Diabetes, vol. 44, no. 7, pp. 775-782, 1995.

[33] G. Hampson, C. Evans, R. J. Petitt et al., "Bone mineral density, collagen type $1 \alpha 1$ genotypes and bone turnover in premenopausal women with diabetes mellitus," Diabetologia, vol. 41, no. 11, pp. 1314-1320, 1998.

[34] Y. Kawashima, J. C. Fritton, S. Yakar et al., "Type 2 diabetic mice demonstrate slender long bones with increased fragility secondary to increased osteoclastogenesis," Bone, vol. 44, no. 4, pp. 648-655, 2009.

[35] R. G. Paul and A. J. Bailey, "Glycation of collagen: the basis of its central role in the late complications of ageing and diabetes," International Journal of Biochemistry and Cell Biology, vol. 28, no. 12, pp. 1297-1310, 1996.

[36] P. L. Selby, “Osteopenia and diabetes," Diabetic Medicine, vol. 5, no. 5, pp. 423-428, 1988.

[37] P. McNair, C. Christiansen, M. S. Christensen et al., "Development of bone mineral loss in insulin-treated diabetes: a $11 / 2$ years follow-up study in sixty patients," European Journal of Clinical Investigation, vol. 11, no. 1, pp. 55-59, 1981.

[38] Y. Seino and H. Ishida, "Diabetic osteopenia: pathophysiology and clinical aspects," Diabetes/Metabolism Reviews, vol. 11, no. 1, pp. 21-35, 1995.

[39] H. Ishida, Y. Seino, T. Taminato et al., "Circulating levels and bone contents of bone $\gamma$-carboxyglutamic acid-containing protein are decreased in streptozocin-induced diabetes: possible marker for diabetic osteopenia," Diabetes, vol. 37, no. 6, pp. 702706, 1988.

[40] A. B. Anwana and H. O. Garland, "Renal calcium and magnesium handling in experimental diabetes mellitus in the rat," Acta Endocrinologica, vol. 122, no. 4, pp. 479-486, 1990.

[41] R. T. Loder, "The influence of diabetes mellitus on the healing of closed fractures," Clinical Orthopaedics and Related Research, no. 232 , pp. 210-216, 1988.

[42] L. Cozen, "Does diabetes delay fracture healing?" Clinical Orthopaedics and Related Research, vol. 82, pp. 134-140, 1972.

[43] W. A. Tyndall, H. A. Beam, C. Zarro, J. P. O’Connor, and S. S. Lin, "Decreased platelet derived growth factor expression during fracture healing in diabetic animals," Clinical Orthopaedics and Related Research, vol. 408, pp. 319-330, 2003.

[44] A. Gandhi, C. Dumas, J. P. O'Connor, J. R. Parsons, and S. S. Lin, "The effects of local platelet rich plasma delivery on diabetic fracture healing," Bone, vol. 38, no. 4, pp. 540-546, 2006.

[45] H. L. Gooch, J. E. Hale, H. Fujioka, G. Balian, and S. R. Hurwitz, "Alterations of cartilage and collagen expression during fracture healing in experimental diabetes," Connective Tissue Research, vol. 41, no. 2, pp. 81-91, 2000.

[46] C. Wallace, G. E. Reiber, J. LeMaster et al., "Incidence of falls, risk factors for falls, and fall-related fractures in individuals with diabetes and a prior foot ulcer," Diabetes Care, vol. 25, no. 11, pp. 1983-1986, 2002.

[47] S. S. Johnston, C. Conner, M. Aagren, K. Ruiz, and J. Bouchard, "Association between hypoglycaemic events and fall-related fractures in Medicare-covered patients with type 2 diabetes," Diabetes, Obesity and Metabolism, vol. 14, no. 7, pp. 634-643, 2012.

[48] "Lifetime benefits and costs of intensive therapy as practiced in the diabetes control and complications trial," The Journal of the American Medical Association, vol. 276, no. 17, pp. 1409-1415, 1996.
[49] M. M. Campos Pastor, P. J. López-Ibarra, F. Escobar-Jiménez, M. D. Serrano Pardo, and A. García-Cervigón, "Intensive insulin therapy and bone mineral density in type 1 diabetes mellitus: a prospective study," Osteoporosis International, vol. 11, no. 5, pp. 455-459, 2000.

[50] P. R. Cavanagh, J. A. Derr, J. S. Ulbrecht, R. E. Maser, and T. J. Orchard, "Problems with gait and posture in neuropathic patients with insulin-dependent diabetes mellitus," Diabetic Medicine, vol. 9, no. 5, pp. 469-474, 1992.

[51] M. F. Holick, "Vitamin D deficiency," The New England Journal of Medicine, vol. 357, no. 3, pp. 266-281, 2007.

[52] D. Bilik, L. N. McEwen, M. B. Brown et al., "Thiazolidinediones and fractures: evidence from translating research into action for diabetes," The Journal of Clinical Endocrinology \& Metabolism, vol. 95, no. 10, pp. 4560-4565, 2010.

[53] P. Vestergaard, L. Rejnmark, and L. Mosekilde, "Are antiresorptive drugs effective against fractures in patients with diabetes?" Calcified Tissue International, vol. 88, no. 3, pp. 209-214, 2011. 


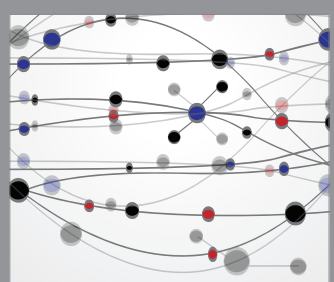

The Scientific World Journal
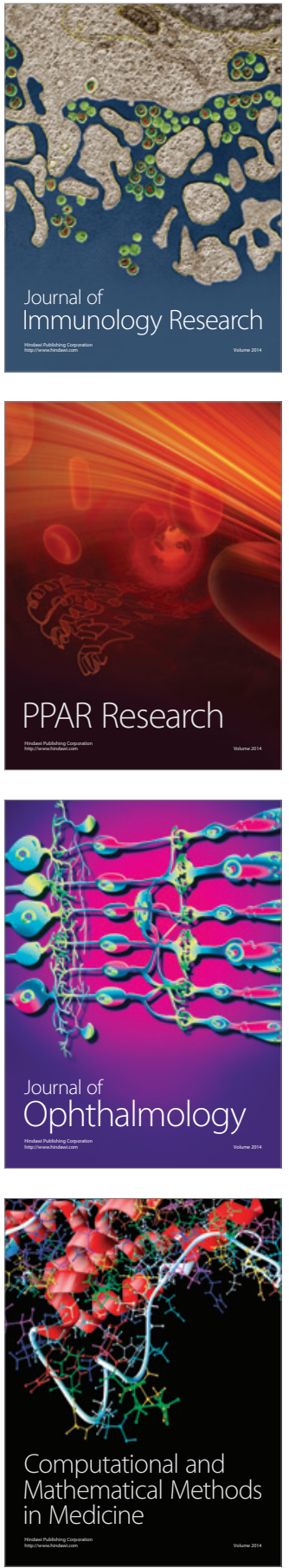

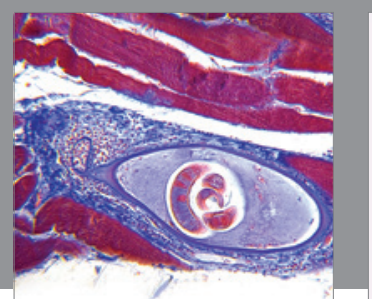

Gastroenterology Research and Practice

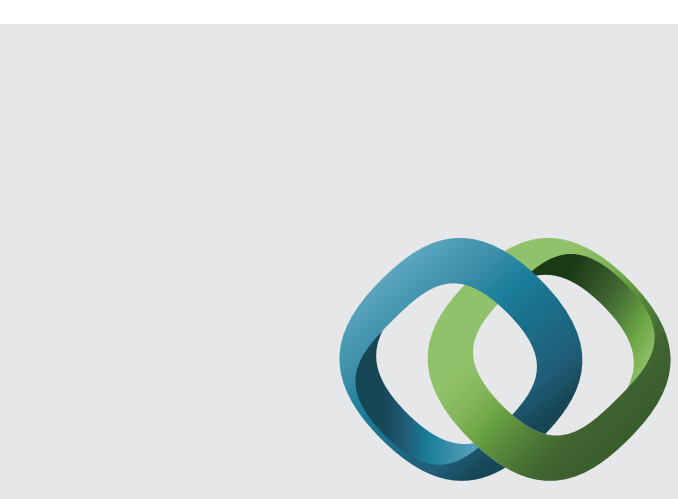

\section{Hindawi}

Submit your manuscripts at

http://www.hindawi.com
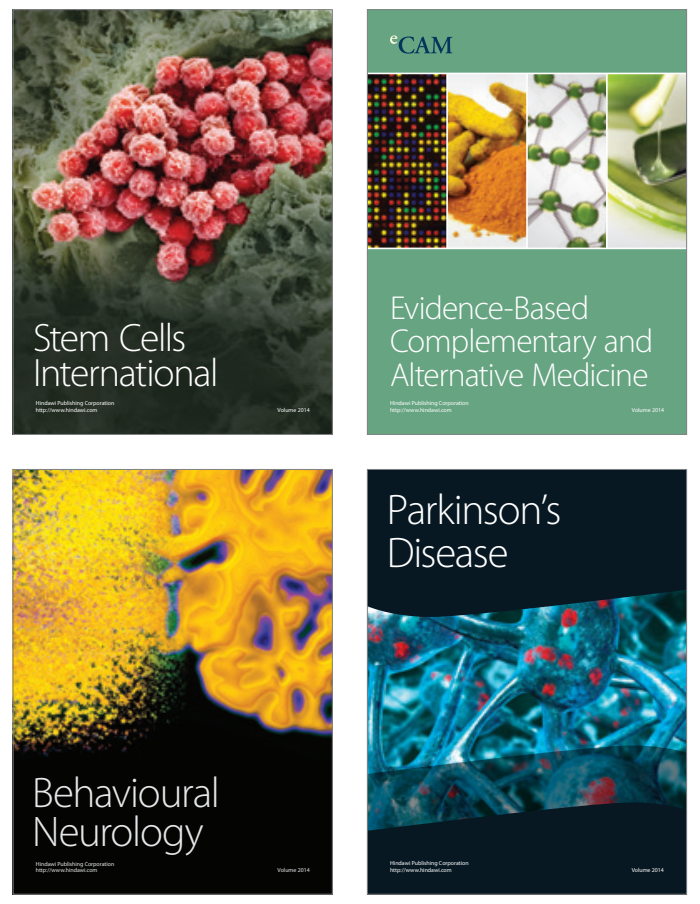
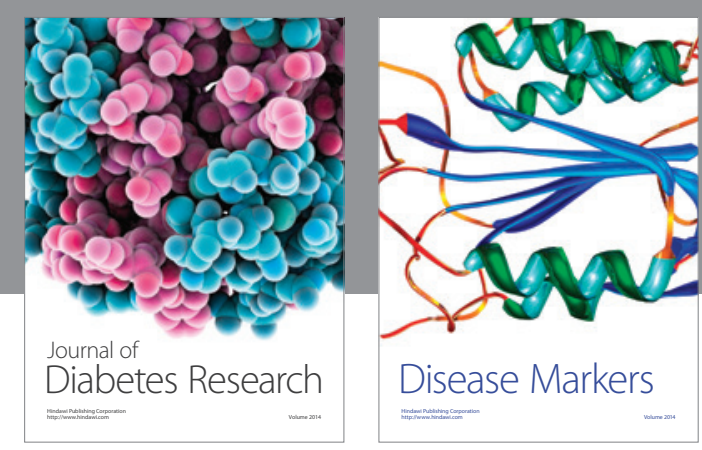

Disease Markers
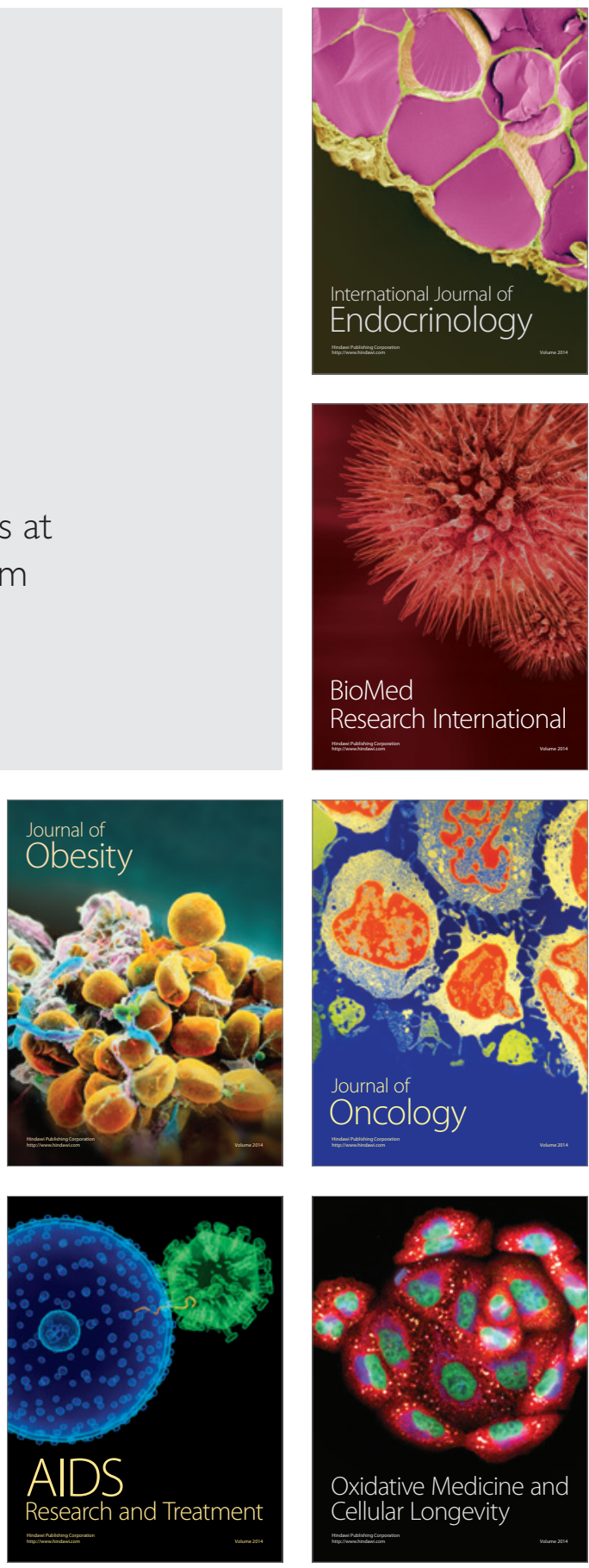